\title{
The two faces of reactive oxygen species (ROS) in adipocyte function and dysfunction
}

DOI 10.1515/hsz-2015-0305

Received December 16, 2015; accepted March 8, 2016; previously published online March 30, 2016

\begin{abstract}
White adipose tissue (WAT) is actively involved in the regulation of whole-body energy homeostasis via storage/release of lipids and adipokine secretion. Current research links WAT dysfunction to the development of metabolic syndrome (MetS) and type 2 diabetes (T2D). The expansion of WAT during oversupply of nutrients prevents ectopic fat accumulation and requires proper preadipocyte-to-adipocyte differentiation. An assumed link between excess levels of reactive oxygen species (ROS), WAT dysfunction and T2D has been discussed controversially. While oxidative stress conditions have conclusively been detected in WAT of T2D patients and related animal models, clinical trials with antioxidants failed to prevent T2D or to improve glucose homeostasis. Furthermore, animal studies yielded inconsistent results regarding the role of oxidative stress in the development of diabetes. Here, we discuss the contribution of ROS to the (patho)physiology of adipocyte function and differentiation, with particular emphasis on sources and nutritional modulators of adipocyte ROS and their functions in signaling mechanisms controlling adipogenesis and functions of mature fat cells. We propose a concept of ROS balance that is required for
\end{abstract}

\footnotetext{
*Corresponding author: José Pedro Castro, German Center for Diabetes Research (DZD), München-Neuherberg, Ingolstädter Landstraße 1 D-85764, Germany; Faculty of Medicine, Department of Experimental Biology, Alameda Prof. Hernâni Monteiro, 4200-319, University of Porto, Portugal; and Institute for Innovation and Health Research, Aging and Stress Group, R. Alfredo Allen, 4200-135 Porto, Portugal, e-mail: jose.castro@dife.de

Tilman Grune: German Center for Diabetes Research (DZD), München-Neuherberg, Ingolstädter Landstraße 1 D-85764, Germany; University of Potsdam, Institute of Nutritional Science, Department of Physiology and Pathophysiology, Arthur-ScheunertAllee 114-116, D-14558 Nuthetal, Germany; and German Center for Cardiovascular Research (DZHK), Postfach 652133 13353, Berlin, Germany

Bodo Speckmann: German Institute of Human Nutrition PotsdamRehbrücke, Department of Molecular Toxicology, Arthur-ScheunertAllee 114-116, D-14558 Nuthetal, Germany
}

normal functioning of WAT. We explain how both excessive and diminished levels of ROS, e.g. resulting from over supplementation with antioxidants, contribute to WAT dysfunction and subsequently insulin resistance.

Keywords: adipogenesis; adipose tissue dysregulation; antioxidants; metabolic disorders; oxidative stress.

\section{Introduction}

Incidence rates of diseases that are collectively referred to as 'metabolic disorders', e.g. metabolic syndrome (MetS), type 2 diabetes (T2D) and cardiovascular diseases are continuously on the rise in Western countries and overburden public health systems. Development of more powerful prevention strategies are therefore urgently needed and require a deeper understanding of the etiology of these related diseases. Common to all metabolic disorders is a dysregulation of the body's energy homeostasis, which is maintained under physiological conditions by a regulatory network of specialized organs such as liver, skeletal muscle, brain and (brown and white) adipose tissue. White adipose tissue (WAT) stores and releases fatty acids depending on energy availability or requirement. WAT constitutes the main energy depot of the human body, and its functional core unit is the adipocyte. Since the discovery of leptin and other adipocyte-secreted hormones, WAT has been recognized as an endocrine organ that is actively involved in the regulation of energy and nutrient homeostasis, the modulation of immune function, angiogenesis and blood pressure. WAT dysfunction is consequently linked to metabolic disorders, such as MetS, T2D and atherosclerosis (Lau et al., 2005). A major risk factor for WAT dysfunction is obesity. Obesity-related oxidative stress has been viewed as a trigger of the underlying pathophysiology. This concept has been valuable to understand some aspects of associated metabolic disorders and their attenuation by pharmaceuticals/nutraceuticals, particularly in rodent studies (reviewed in Le Lay et al., 2014). However, the concept has been challenged 
by findings from epidemiologic and mechanistic studies, showing a lack of benefit or even adverse effects of antioxidant supplementation, as well as the identification of ROS as second messengers of insulin-triggered signaling. In this review we will discuss the participation of ROS in WAT functions, how dysregulated ROS levels can lead to adipocyte dysfunction, and how these effects are modulated by interventions (e.g. dietary antioxidants).

\section{Adipocytes and energy homeostasis}

In mammals, there are two types of adipose tissue: brown adipose tissue (BAT) and WAT. Both types consist primarily of adipocytes and their precursor cells which differentiate to mature adipocytes in a process called adipogenesis. In addition to these cells, adipose tissues contain macrophages, fibroblasts, leukocytes, and endothelial cells, whereby their relative proportions are dependent on the metabolic and inflammatory stage of the tissue. Brown adipocytes are specialized in heat generation and energy expenditure by uncoupled mitochondrial oxidation of nutrients at the expense of ATP generation. The primary function of white adipocytes is to store and release lipids. These lipids are stored mainly in the form of triacylglycerides (TG) which are formed after resorption of fatty acids derived from circulating lipoproteins and their intracellular esterification with glycerol-3-phosphate. Adipocytes are also capable of de novo fatty acid synthesis using acetyl-CoA derived from glucose, glutamine and ketone bodies (Yoo et al., 2004). Under conditions of excess caloric intake, TG accumulates in large, single lipid droplets and the adipocytes become enlarged and/ or new adipocytes differentiate from preadipocytes. Lipid droplets are associated with a set of proteins like perilipin 1 (PLIN1), CIDE proteins and caveolins, which control storage and hydrolysis of TG and have emerged as important factors to prevent hyperlipidemia-triggered insulin resistance (Konige et al., 2014). The release of fatty acids from WAT is controlled both by hormones that regulate intracellular lipases and by the rate of glucose uptake from plasma because glucose serves as a precursor of glycerol-3-phosphate and acetyl-CoA.

\section{Adipogenesis}

Healthy adipose tissue depends on continuous renewal of its cells, foremost adipocytes. In WAT, adipocytes differentiate from multipotent mesenchymal stem cells (MSCs) in a multi-step process called adipocyte differentiation or adipogenesis. Mechanistic insight into adipogenesis has been obtained by the use of in vitro cultivated MSCs (Pittenger et al., 1999; Tormos et al., 2011) and preadipocyte cell lines (Mackall et al., 1976; Poulos et al., 2010) exposed to proadipogenic hormone cocktails, while primary mature adipocytes are particularly useful for studying acute adipocyte functions like uptake of hexose sugars (Sandra and Fyler, 1981). Commitment of adiposederived stem cells to adipocyte progenitor cells requires the presence of the ribosomal protein S6 kinase 1 (S6K1) (Carnevalli et al., 2010). Key executors of the terminal differentiation program are the transcription factors CCAAT/enhancer binding protein (C/EBP) $\beta$ followed by peroxisome proliferator-activated receptor (PPAR) $\gamma$ and $\mathrm{C} / \mathrm{EBP} \alpha$, which along with additional factors induce the expression of adipocyte-specific genes, like adiponectin and adipocyte protein 2 (Wu et al., 1999). Sustained expression of PPAR $\gamma$ is then required to maintain the differentiated state and the functionality of mature adipocytes (Tamori et al., 2002). PPAR $\gamma$ and C/EBP $\alpha$ integrate signals elicited by extracellular growth factors that act as inducers of adipogenesis, such as insulin, insulin-like growth factor 1 (IGF1), fibroblast growth factor, and transforming growth factor $\beta$, as well as of anti-adipogenic Wnt factors (Rosen and MacDougald, 2006; Wang et al., 2010a,b). Signaling pathways initiated by insulin/IGF1 receptor tyrosine kinases are active during adipogenesis. They act most notably via the Akt kinase and its targets protein kinase $\mathrm{C}$ (PKC) isoforms and mammalian target of rapamycin complex-1 (mTORC1) to promote differentiation (Gagnon et al., 2001; Peng et al., 2003) along with PPAR $\gamma$ and $\mathrm{C} / \mathrm{EBP} \alpha$ protein expression (Kim and Chen, 2004; Tormos et al., 2011) (Figure 1). Another important factor in adipogenesis is NADPH oxidase (NOX) 4. NOX4 was shown to act as a switch between proliferation and differentiation of adipocytes by inhibition of ERK1/2, which performs an inhibitory serine phosphorylation of insulin receptor substrate 1 (IRS1) that prevents insulin receptor-triggered tyrosine phosphorylation of IRS1, required for subsequent activation of phosphatidylinositol 3-kinase (PI3K). ERK1/2 inhibition by NOX4 is mediated by MAP kinase phosphatase-1 (MKP-1) (Schroder et al., 2009). This activation of MKP-1 requires the formation of hydrogen peroxide $\left(\mathrm{H}_{2} \mathrm{O}_{2}\right)$ by NOX4, and an exogenous addition of the superoxide dismutation product $\mathrm{H}_{2} \mathrm{O}_{2}$ was sufficient to trigger adipogenesis even in the absence of insulin. An important downstream effector of adipocyte mTOR signaling is S6K1, as it promotes not only protein translation but also mediates inhibition of insulin signaling in high fat diet mice (Um et al., 2004). Besides growth factors, amino acids and glucose are also known to 


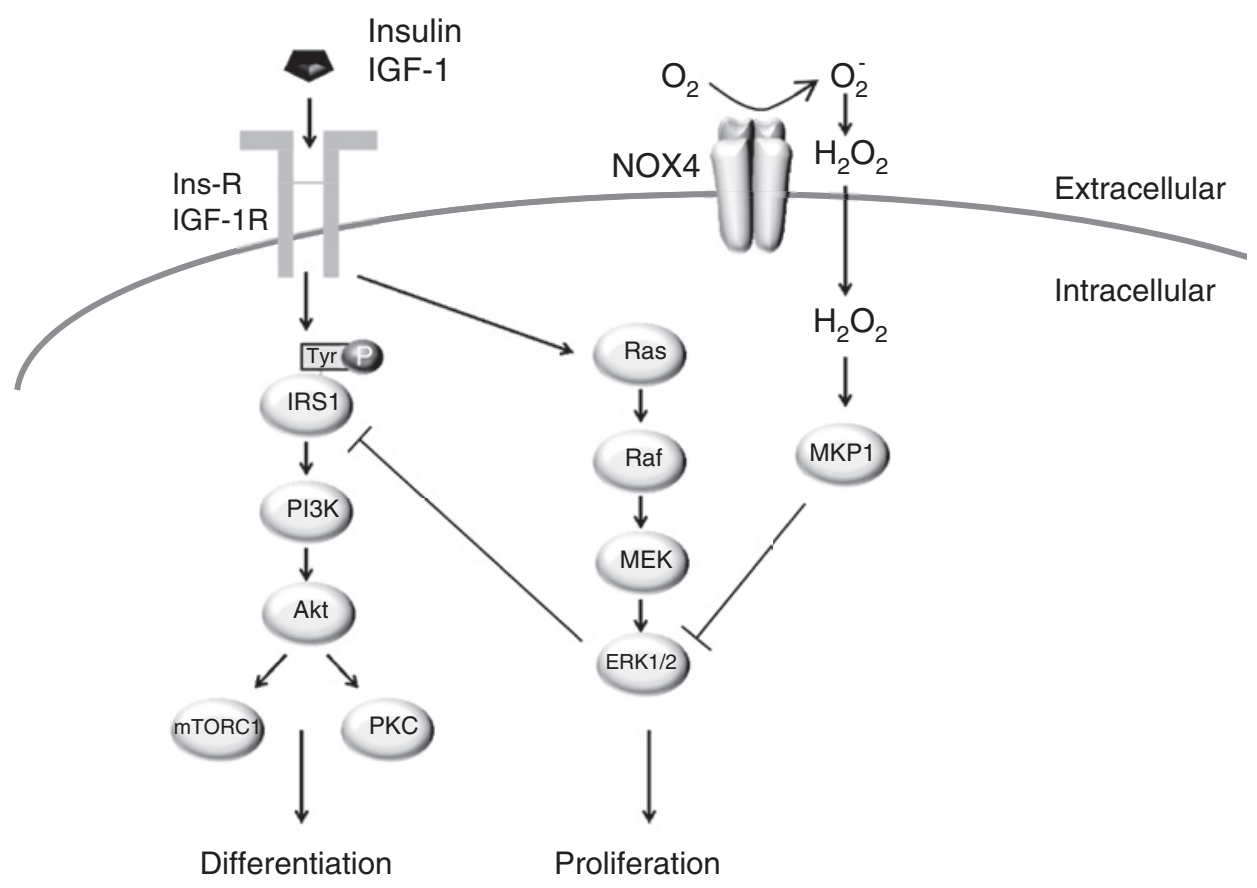

Figure 1: Adipogenic signaling by insulin and NOX4.

Insulin and IGF-1 signaling is initiated by binding to InsR and IGF-1R, leading to tyrosine phosphorylation of IRS1. Subsequent phosphorylation of PI3K and Akt results in activation of mTORC1 and PKC, which promotes adipogenic differentiation. Insulin also signals through Ras/ Raf/MEK/ERK1/2 to stimulate proliferation of preadipocytes, with concurrent inhibitory serine phosphorylation of IRS1. ERK1/2 activation however is attenuated by MKP1, which in turn is activated by NOX4-derived $\mathrm{H}_{2} \mathrm{O}_{2}$ at early stages of adipocyte differentiation. ERK1/2, mitogen-activated protein kinase 3/1; IGF-1R, insulin-like growth factor 1 (IGF-1) receptor; InsR, insulin receptor; IRS1, insulin receptor substrate 1; MKP1, MAP kinase phosphatase 1; NOX4, NADPH oxidase 4; PI3K, phosphatidylinositol 3-kinase; PKC, protein kinase C.

activate mTORC1. Hence it integrates various nutritional and hormonal signals to promote the expansion of WAT under sustained nutrient excess. Redox states of major intracellular redox pairs (oxidized/reduced glutathione, thioredoxin, and cysteine) (Imhoff and Hansen, 2011) as well as ROS, such as the NOX4-generated $\mathrm{H}_{2} \mathrm{O}_{2}$ have been recognized as important modulators of adipogenesis and adipose tissue function in health and disease. Other factors that regulate adipogenesis involve epigenetic mechanisms, as shown by several recent investigations in the epigenetic landscape of differentiating adipocytes. These studies described extensive chromatin remodeling occurring during early adipogenesis (Siersbaek et al., 2011) and highlight the importance of histone code transformation near adipogenic genes and differential expression of histone-modifying enzymes, e.g. the histone demethylase PHF2 (Lee et al., 2014) and histone methyltransferases EZH2 (Hemming et al., 2014) and G9a (Wang et al., 2013a,b), for the differentiation process. A genomewide methylation analysis compared adipose-derived stem cells and mature adipocytes and found that the DNA methylome remained relatively stable during adipogenesis. In contrast, some late expressing adipogenic genes, e.g. adiponectin and adiponectin receptor 2, that are targeted by PPAR $\gamma$, showed differential methylation within their PPAR $\gamma$ DNA binding sites at later stages of adipogenesis (Takada et al., 2014). PPAR $\gamma$ has been shown to induce local DNA demethylation at its binding sites via poly(ADP-ribosyl)ation of the transcription factor/coactivator complex and subsequent recruitment of Tet proteins that oxidize 5-methylcytosine $(5-\mathrm{mC})$ to 5-hydroxymethylcytosine, resulting in the replacement of $5-\mathrm{mC}$ by cytosine (Fujiki et al., 2013). It can be concluded that the DNA methylome of mature adipocytes develops early in the lineage differentiation, and that the large majority of adipocyte genes is 'ready' for transcriptional induction as early as the preadipocyte stage. The limiting and necessary factor is PPAR $\gamma 2$, whose expression and DNA binding activity are controlled by epigenetic mechanisms during adipogenesis (Fujiki et al., 2009; LeBlanc et al., 2012; Wang et al., 2013a,b). Interestingly, the expression of PPAR 22 was reduced in the adipose tissue of diabetic mice, and this was due to repressive methylation of its promoter region (Fujiki et al., 2009), indicating that DNA methylation of PPAR $\gamma 2$ is important for adipose tissue (dys)function. 


\section{Adipocyte dysfunction in metabolic disorders: manifestation, causes and consequences}

Dysfunction of insulin-producing $\beta$-cells and peripheral insulin resistance are considered as the main drivers of T2D pathology and related disorders belonging to MetS. The overall estimate on T2D heritability is between $10 \%$ and 20\% (Drong et al., 2012), while the common and main risk factor for T2D and MetS is obesity (Kahn et al., 2006). Adipose tissue has been given increased attention in the field of diabetes research, as current findings indicate that adipocyte dysfunction is intimately connected with the development of insulin resistance, MetS, and also atherosclerosis. The hallmarks of adipocyte dysfunction are (i) the cells' inability to store excess nutrients as intracellular lipids, resulting in lipid spillover into the blood and subsequent ectopic fat accumulation (e.g. in liver, skeletal muscle, pancreas and myocardium) with occurrence of lipotoxic events, and (ii) dysregulated secretion of adipokines with consequences for WAT homeostasis and for whole body energy metabolism. As for the principal causes of these problems, impaired adipogenesis and impaired function of mature fat cells can be envisaged. An emerging view is that while in chronic adipose tissue dysfunction both adipogenesis and fat cell function are compromised, the impairment of adipogenesis precedes the manifestation of adipose tissue dysfunction and seems to be more crucial for tissue impairment. Therefore, the underlying mechanisms of adipogenesis failure are of particular relevance for means of prevention. In this chapter we will briefly describe how adipocyte dysfunction is manifested in humans and animals and give a short overview of its causes and consequences with respect to the metabolic disorders mentioned. Adipocyte growth beyond a critical volume is thought to go along with functional impairments (Guilherme et al., 2008) and increased risk of T2D (Cotillard et al., 2014). The volume that can be tolerated without compromising the adipocyte's function appears to depend on individual parameters that have yet to be fully understood. A concept of exceeded adipose tissue expandability causing adipocyte dysfunction and T2D has previously been described (Virtue and Vidal-Puig, 2010). It is important to note that adipocyte dysfunction and ectopic fat deposition have been shown to precede the manifestation of T2D, which implies that this early defect is a causal event for T2D. Park et al. compared the adipogenic potential of ex vivo cultured preadipocytes derived from subcutaneous fat depots of obese women with and without the MetS (Park et al., 2012). They found that healthy obese women had a significantly higher capability of preadipocyte differentiation than obese women suffering from the MetS. Preadipocyte differentiation was inversely correlated with plasma TG levels and homeostasis model assessment of insulin resistance, corroborating the concept that a high adipogenic potential and lipid storing capacity of fat tissue predicts healthier metabolic profiles. Moreover, mutations in PPAR $\gamma$ (Barroso et al., 1999) and key adipogenic genes involved in lipid droplet formation like Seipin/BCSL2, Caveolin 1 (CAV-1), PLIN1, and 1-acylglycerol-3-phosphate O-acyltransferase 2 (AGPAT2) go along with reduced adipose tissue mass and/or expansion capacity, lipodystrophy and insulin resistance in humans and in transgenic mice [reviewed in (Vigouroux et al., 2011; Konige et al., 2014)]. Adipocyte hypertrophy has been associated with an impairment of insulin-stimulated glucose uptake, increased lipolysis, leptin secretion and increased secretion of pro-inflammatory cytokines interleukin (IL)-6, IL-8, TNF $\alpha$, chemokine (C-C motif) ligand 2 (CCL2) and reduced secretion of adiponectin and IL-10. Similar differences in the adipokine profiles were found in the supernatants of ex vivo cultured subcutaneous adipose tissue from MetS compared to control subjects (Bremer and Jialal, 2013), additionally showing increased levels of retinol binding protein 4, C-reactive protein, serum amyloid A1, serpin peptidase inhibitor clade E member 1 and IL-1 $\beta$ in the MetS group. The secretome of dysfunctional WAT therefore contributes to a chronic pro-inflammatory state locally and systemically and, via an imbalanced secretion of insulin sensitizing (adiponectin) and inhibiting (TNF $\alpha$, CCL2) adipokines, to increased insulin resistance. Low-grade inflammation of WAT in MetS and in obese subjects has also been evidenced by macrophage infiltration (Cancello et al., 2005; Bremer and Jialal, 2013), which correlates with mean adipocyte size and with body mass (Weisberg et al., 2003). Recruitment of macrophages is facilitated by the inflammatory cytokine osteopontin, which has been shown to be overexpressed in the adipose tissue of diabetic (Nilsson et al., 2014) and obese (Pietilainen et al., 2008) monozygotic twins compared to their non-diabetic and lean siblings, respectively. Local inflammation within the WAT exacerbates adipocyte dysfunction via effects on adipocyte metabolism and differentiation. Particularly important in this regard is macrophage-derived $\mathrm{TNF} \alpha$ (Weisberg et al., 2003), which has been shown to enhance FFA release and attenuate adipogenesis via downregulation of PPAR $\gamma$ expression. TNF $\alpha$-triggered increase in lipolysis results not only from impaired insulin signaling, but also from diminished expression and activity of the lipid droplet-associated protein PLIN1 (Ryden et al., 2004), where lipases gain access to the lipid droplet. Causality of 
PLIN1 failure for T2D development has been substantiated by findings of rare missense mutations in the PLIN1 gene that were associated with dyslipidemia, hepatic steatosis and T2D in human carriers (Gandotra et al., 2011). Since dysregulated ROS levels have been linked to adipocyte dysfunction, in the next two sections we will depict the current understanding of ROS involvement in adipogenesis in healthy and in metabolically unhealthy adipose tissue.

\section{Role of ROS in adipogenesis}

\section{Sources of ROS}

ROS are unstable reactive molecules which can oxidize (therefore oxidants) important cellular constituents, such as lipids, DNA or proteins (Halliwell, 2006). Common examples of ROS include the superoxide anion $\left(\mathrm{O}_{2}^{-*}\right)$, $\mathrm{H}_{2} \mathrm{O}_{2}$, and the hydroxyl radical $\left(\mathrm{OH}^{\circ}\right)$. Their effects at a cellular level are largely dependent on the species itself, its concentration, location and likely time of exposure. For example, $\mathrm{OH}^{\prime}$ has a half-life of only a few nanoseconds, however, it is extremely reactive causing immediate damage on nearby biomolecules directly after its formation (Stadtman and Levine, 2000). However, $\mathrm{H}_{2} \mathrm{O}_{2}$ can be stable for a longer time (up to minutes in aqueous solutions - in vivo the mean half-life is shorter due to the presence of reducing substrates/enzymes) and participate in cellular signaling, e.g. insulin-triggered signaling, via reversible oxidation of cysteines. However, higher concentrations of ROS can result in irreversible oxidation and thus functional impairment of biomolecules (Sies, 2014). Cells are affected by ROS from either exogenous or endogenous sources. Endogenously, these species are formed as unintended by-products or by specific enzymatic reactions. The main endogenous sources are the mitochondria, NADPH oxidases, nitric oxide synthases, Fenton reaction, microsomal cytochrome $\mathrm{P} 450$ oxidases, peroxisomal $\beta$-oxidation, prostaglandin synthesis, and others (Halliwell, 2006; Hohn et al., 2013). Generally, mitochondria are considered the most relevant cellular ROS producer, because of their continuous action during metabolism (Rigoulet et al., 2011). In fact, the mitochondrial electron transfer chain is a major production site in adipocytes from mice (Wang et al., 2010a,b) and from isolated mitochondria showing that $0.2 \%-2 \%$ of consumed $\mathrm{O}_{2}$ is reduced by single electrons, generating $\mathrm{O}_{2}^{--}$as a byproduct (Brand, 2010) especially by complex I (NADH dehydrogenase) and complex III (cytochrome bc1 complex) (Fisher-Wellman and Neufer, 2012). High ROS levels produced by dysfunctional mitochondria have been suggested as the main cause of aging (Barja, 2014), resulting from error accumulation impinged on biomolecules. Interestingly, the aging process has been shown to share similar features with dysfunctional adipose tissue; for example, obesity contributes to reduced life span and the clinical outcomes closely resemble those usually found in aging (Ahima, 2009). Therefore, obesity might result in adipose tissue dysfunction via impairment of mitochondrial function with excessive ROS production. Another important generator of ROS in adipocytes are the NOXs (Bedard and Krause, 2007), membrane-bound proteins which transfer electrons from NADPH to $\mathrm{O}_{2}$. From the seven isoforms of catalytic subunits identified in mammalian cells, NOX4 is the most abundant isoform in adipocytes (Mahadev et al., 2004), and its expression is further increased in fat cells exposed to excess glucose or palmitate (Mahadev et al., 2004). Supporting its role as an important ROS producer in adipocytes, silencing NOX 4 in 3T3-L1 preadipocytes inhibited glucose and palmitateinduced ROS formation (Han et al., 2012). In another study, Schröder et al. showed that NOX4 was indispensable for insulin-dependent differentiation of 3T3-L1 preadipocytes (Schroder et al., 2009). Mitochondria and NOXs appear as crucial ROS sources in adipocytes, and furthermore a regulatory crosstalk between these sources has been proposed (Dikalov, 2011). In the following two chapters we will summarize the current understanding of the role of ROS in adipogenesis and insulin signaling.

\section{Requirement of ROS for adipogenesis and insulin signaling}

'A disturbance in the prooxidant-antioxidant balance in favor of the former', this was how oxidative stress was initially viewed, a condition known to promote potential damage (Sies, 2015). However, insights on specific redox regulatory effects of ROS support the idea that, when balanced, ROS play an important role in signal transduction cascades (Sies, 2015). This newer perspective has been built upon numerous evidence showing several signaling pathways to be redox-regulated by means of dynamical shifting of the ratio between oxidized/reduced amino acids within mediators of these pathways (Hensley et al., 2000). For instance, reversible oxidation of specific cysteines can either render phosphatase and tensin homolog (PTEN) protein activation or cdc25 protein inhibition, two proteins that modulate cellular proliferation (Cho et al., 2004). Additionally, mechanisms of proteostasis 
such as macroautophagy can be triggered by oxidation of cysteines within the Atg4 enzyme (Scherz-Shouval et al., 2007). Adding to this, activation of the nuclear factor (erythroid-derived 2)-like 2 (Nrf2) transcription factor is also ROS-dependent: upon a mild increase in the levels of ROS, reversible oxidation of specific cysteines of the Nrf2inhibitor Keap1 render it inactive, resulting in detachment of Nrf2, which subsequently translocates to the nucleus (Zhang and Hannink, 2003). ROS have been implicated in the regulation of several processes such as cytokine secretion, proliferation, differentiation, gene expression and as cytotoxic molecules in immune responses against invading pathogens (Hensley et al., 2000). A study with H4IIEC hepatoma cells showed that different $\mathrm{H}_{2} \mathrm{O}_{2}$ concentrations could either enhance, if in a low concentration such as $5 \mu \mathrm{M}$, or repress, if in a high concentration such as $50 \mu \mathrm{M}$, the insulin signaling pathway (Iwakami et al., 2011). Remarkably, adipocytes seem to adapt to dynamic changes in ROS levels and to use them as second messengers. $\mathrm{H}_{2} \mathrm{O}_{2}$ was found to mimic insulin action: exposure of adipocytes to $\mathrm{H}_{2} \mathrm{O}_{2}$ resulted in a rapid translocation of glucose transporters and increased glucose uptake (Kono et al., 1982), increased lipid synthesis (May and de Haen, 1979), whereas lipolysis was blunted (Little and de Haen, 1980). Moreover, a study by Lee et al. evidenced that during adipogenic mitotic clonal expansion, $\mathrm{H}_{2} \mathrm{O}_{2}$ - and hormonetreated 3T3-L1 preadipocytes showed acceleration in their differentiation with increased PPAR $\gamma 2$ expression and cell cycle progression (Lee et al., 2009). However, when N-acetylcysteine was added to the medium, an S-phase arrest in the cell cycle was noted. Altogether, the authors found a necessary redox signaling regarding $\mathrm{C} / \mathrm{EBP} \beta$ binding to DNA for PPAR $\gamma 2$ transcription, an important feature of terminal adipogenesis (Lee et al., 2009). ROS have been shown to increase insulin sensitivity (Loh et al., 2009). Evidence is provided for example from protein tyrosine phosphatase inhibition by $\mathrm{H}_{2} \mathrm{O}_{2}$, leading to the enhancement of protein tyrosine phosphorylation signaling in the early insulin cascade pathway (Mahadev et al., 2001). A study by Tormos and colleagues (Tormos et al., 2011) emphasized mitochondrial ROS dependence for adipocyte differentiation by showing that specific mitochondrial antioxidants such as Mitotempol or MitoCP resulted in abrogation of adipogenesis; and mitochondrial complex III was identified in the same study as the ROS (superoxide) source relevant for adipogenesis via activation of PPAR $\gamma 2$. While these studies demonstrate the requirement of limited ROS levels for adipogenesis, ROS may also impede with cellular functions if their levels peak or if they become persistent in cells (Figure 2).

\section{Consequences of ROS imbalance for adipocyte functionality}

This chapter is focused on the harmful effects of imbalanced ROS levels during oxidative stress, which has been linked to adipocyte dysfunction. In contrast to reversible oxidation mentioned above, proteins can become irreversibly oxidized depending on ROS type. A particularly relevant event in this regard is protein carbonylation, an

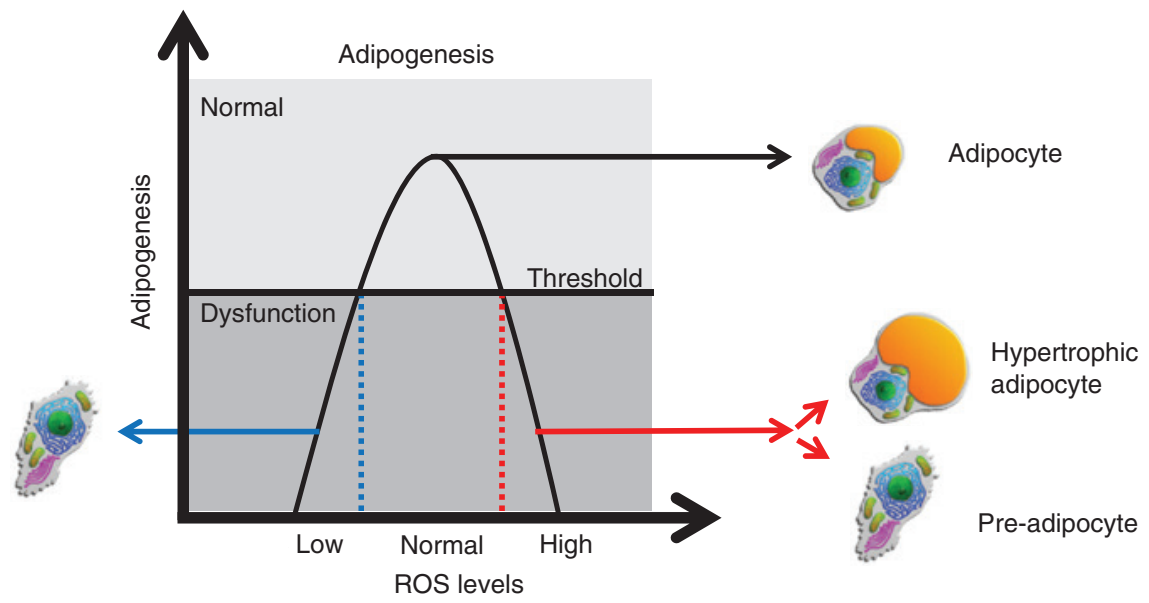

Figure 2: The importance of physiological ROS levels for adipogenic differentiation.

Several studies support the crucial role of ROS for adipogenesis to progress through a well-orchestrated process (central position) for the cell to become a mature adipocyte, shown by the rounded cell shape with a major lipid droplet (in orange). However, below or above a certain ROS level adipogenesis fails to progress, shown by an elongated fibroblast-like structure (left and right side), or is involved in the formation of hypertrophic adipocytes, shown by the rounded cell shape with an increased lipid droplet (right side). 
irreversible non-enzymatic modification, that can lead to protein dysfunction and aggregation (Nyström, 2005; Castro et al., 2012). This protein modification is regarded as a severe marker of protein oxidation and dysfunction, shown to accumulate during aging (and age-related diseases) and in chronic diseases such as chronic renal failure or chronic lung disease (Levine and Stadtman, 2001; Dalle-Donne et al., 2003). Protein carbonylation results either from direct attack by metal-catalyzed ROS at specific amino acid residues such as lysine, threonine, arginine and proline or by secondary attack on lysine, cysteine or histidine from modified aldehydes (from lipid peroxidation) such as 4-hydroxynonenal (4-HNE) or from glycoxidation products (oxidation of carbohydrates) such as glyoxal or methylglyoxal (Stadtman and Levine, 2000; Höhn et al., 2014). Increased levels of carbonylated proteins have also been found in some metabolic disorders such as obesity and T2D (Valerio et al., 2006; Grimsrud et al., 2007; Curtis et al., 2010; Frohnert and Bernlohr, 2013; Bollineni et al., 2014). For example, an association between mitochondrial dysfunction, oxidative stress and carbonylated proteins has been proposed to play a critical role in the development of adipocyte insulin resistance (Frohnert and Bernlohr, 2013). Moreover, carbonylated plasma proteins, e.g. vascular endothelial growth factor-2 (VEGFR-2), matrix metalloproteinase-1 (MMP-1), mitogen-activated protein kinase kinase 4 (MKK4), agrin and compliment C5 proteins, they were suggested as potential biomarkers for obesity-induced T2D (Bollineni et al., 2014). Others have also reported some cellular proteins to be carbonylated and thus impaired in their function in obesity and T2D. Among these are proteins such as adipocyte fatty acid-binding protein (AFABP) (Valerio et al., 2006), glutathione peroxidase 1 (GPX-1), peroxiredoxin 1 (PRDX-1), and $\beta$-enolase (Grimsrud et al., 2007), with roles in lipid binding and lipolysis, antioxidant response, and glycolysis, respectively. Furthermore, related studies have shown evidence of the loss of an antioxidant and 4-HNE-detoxifying protein, glutathione S-transferase 4 (GST4), due to its carbonylation (Valerio et al., 2006; Grimsrud et al., 2007; Curtis et al., 2010). GST4 was found to be a carbonylation target of lipid peroxidation-derived reactive aldehydes arising in obese mice; and this modification led to GST4 downregulation (Grimsrud et al., 2007). Analogous findings were retrieved with 3T3-L1 adipocytes, where treatment with the pro-inflammatory cytokine TNF $\alpha$ caused GST4 carbonylation and downregulation (Curtis et al., 2010).

As a conclusion, increased levels of carbonylated proteins seem to be associated with mitochondrial dysfunction in adipocytes, with possible relevance for the development of insulin resistance.

\section{Proteostasis in adipocytes}

A possible consequence of the formation of oxidized proteins is their propensity to become unfolded and aggregated. Protein aggregation takes place after oxidized proteins expose hydrophobic residues, usually concealed in the protein's core, leading to binding to other oxidized proteins. To prevent the potential hazard of protein aggregation, cells employ turnover mechanisms such as proteasomal turnover (Grune et al., 2003; Jung et al., 2009). This protein degradation system comprises two main forms: the $26 \mathrm{~S}$ proteasome, dependent on ubiquitin tagging of targeted proteins and ATP; and the $20 \mathrm{~S}$ proteasome, which is independent of both ubiquitin and ATP. Oxidized proteins seem to be degraded exclusively by the $20 \mathrm{~S}$ proteasome (Grune et al., 1995, 1996, 1997, 2003; Reinheckel et al., 1998; Ullrich et al., 1999; Davies and Shringarpure, 2006; Jung et al., 2009; Kastle et al., 2012). The 20S proteasome has a barrel shaped structure, composed of $\alpha$ and $\beta$ rings organized in a $\alpha \beta \beta \alpha$ manner; each ring has seven subunits (as $\alpha 1-\alpha 7 ; \beta 1-\beta 7$ ). The inner $\beta$ rings contain the three subunits responsible for specific proteolytic activity: $\beta 1$ for peptidyl-glutamyl-peptide-hydrolyzing or caspase-like activity, $\beta 2$ for trypsin-like activity, and $\beta 5$ for chymotrypsin-like activity. The outer $\alpha$-rings are responsible for substrate detection and binding of regulatory complexes such as $11 \mathrm{~S}$ and $19 \mathrm{~S}$, which determines the activity and the specificity of the proteasome (Davies and Shringarpure, 2006). Thus, any decline in proteasome activity results in impairment of proteostasis, interfering with cellular signaling and function. This view is supported by a study showing that adipose tissue from metabolically unhealthy obese individuals with insulin resistance displayed proteasome inhibition with concomitant accumulation of oxidized and ubiquitinated proteins (Diaz-Ruiz et al., 2015). The authors suggest that this loss of proteostasis underlies the development of insulin resistance in adipocytes from unhealthy obese. Dasuri et al. described proteasome inhibition in relation to impaired adipogenesis under oxidative stress conditions (Dasuri et al., 2011). This study provides evidence that the aging process itself is able to change the activity and expression of different components of the proteasome (Dasuri et al., 2011). This impacts the healthy pool of preadipocytes and adipocytes, which ensures a functioning and dynamic adipose tissue. Therefore, proteasome inhibition has two main consequences that lead to adipose tissue dysfunction; firstly, the impairment of adipogenesis and secondly, an increase of oxidative stress in mature adipocytes, contributing to tissue dysfunction (Dasuri et al., 2011). Accounting for the provided evidence, 
it is reasonable to speculate that metabolic diseases may originate from the occurrence of non-physiological levels of ROS, ultimately resulting in the formation of oxidized proteins and proteasome impairment. Therefore, oxidative stress and the progression of metabolic diseases seem to be closely connected. Until now, we have focused on ROS imbalance generating carbonylated proteins and proteasome inhibition at a cellular level.

In the next section, we will summarize the evidence on how oxidative stress can lead to WAT dysfunction.

\section{Consequences of ROS imbalance for white adipose tissue}

High ROS levels within the WAT promote a disturbed redox balance therein and impact its function via mechanisms, such as impairment of adipogenesis, induction of insulin resistance and adipocyte hypertrophy.

ROS can inhibit the proliferation of adipogenic progenitors (Carriere et al., 2003), although apoptosis was not observed (De Pauw et al., 2009), this results in hypertrophy of the mature adipocytes due to the lack of tissue renewal. Hypertrophic obesity is commonly accepted as more deleterious than hyperplasia and has been associated with insulin resistance (Stern et al., 1972; Lundgren et al., 2007). As discussed earlier, adipocyte hypertrophy can lead to tissue inflammation, altered metabolism and dysregulated adipokine secretion. ROS can directly inhibit respiration promoting lipid accumulation. This is explained by the substrates that cannot be properly oxidized favoring TG storage (Wang et al., 2010a,b). Another risk factor for adipocyte hypertrophy is aging, via the development of mitochondrial dysfunction, which in turn is implicated in excessive lipid storage (Kirkland et al., 1994; Karagiannides et al., 2001; Kirkland et al., 2002). Hypertrophy-induced inflammation might have a basis for oxidative stress establishment (Murdolo et al., 2013). High ROS levels led to a decrease in adiponectin expression and secretion (Wang et al., 2013a,b), an important protein for insulin sensitivity and exhibiting anti-atherogenic and anti-inflammatory effects. Altogether, it seems likely that oxidative stress can trigger hypertrophy of adipocytes and that this is followed by tissue inflammation and dysfunction, once the adipose tissue's expandability is exceeded (Figure 3). In this context, sustained or chronic exposure of 3T3-L1 preadipocytes to micro-molar concentrations of $\mathrm{H}_{2} \mathrm{O}_{2}$ reduced glucose transporter translocation and diminished lipogenesis (Rudich et al., 1997). Furthermore, increasing intracellular amounts of ROS led to mitochondrial dysfunction with diminished insulin signaling and adiponectin secretion in 3T3-L1 cells (Wang et al., 2013a,b). Another study has shown that preadipocyte proliferation was inhibited by mitochondrial ROS, which therefore affect the size of the white adipocyte pool (Carriere et al., 2003). Subcutaneous abdominal fat samples from diabetic compared to obese and non-diabetic control subjects displayed increased levels of lipid peroxidation products such as 4-HNE, linking oxidative stress to insulin resistance (Murdolo et al., 2013). Interestingly, 4-HNE modifies

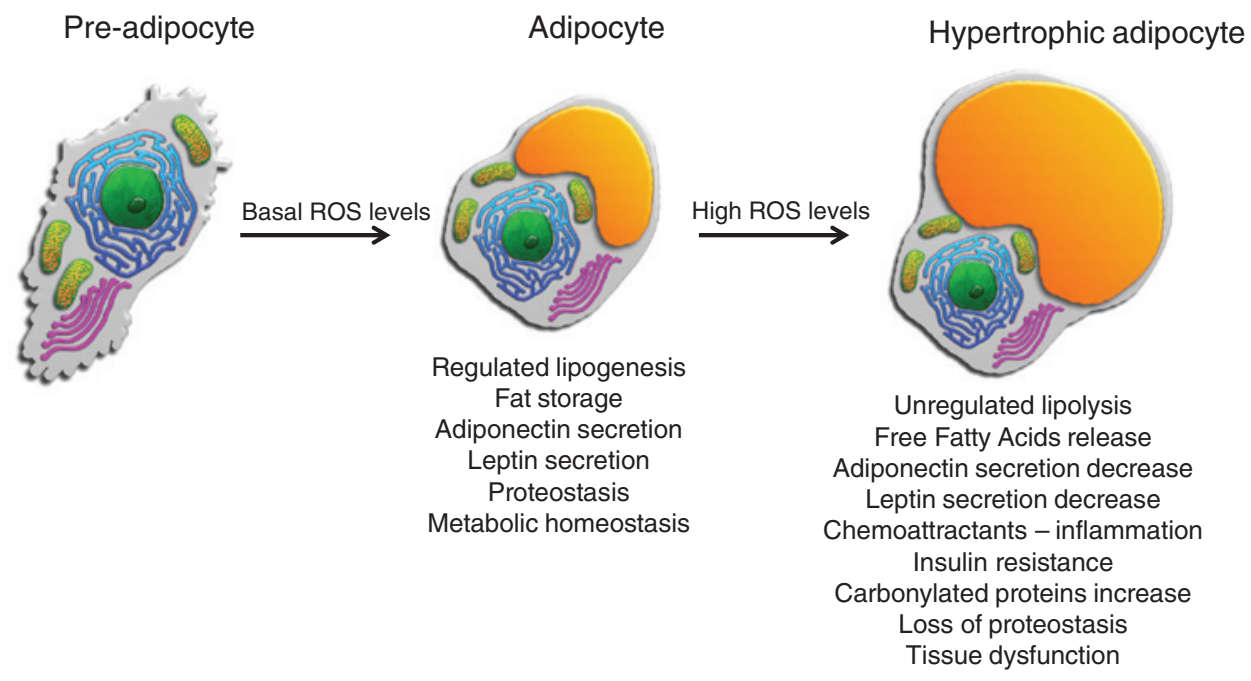

Figure 3: Oxidative stress is originated in overcaloric conditions increasing the risk for several metabolic dysfunction outcomes. Physiological ROS levels are mandatory for a proper adipogenesis contributing to adipose tissue and overall organism homeostasis. If these levels are altered either through external conditions or inherent processes such as aging, the risk for developing hypertrophic adipocytes increases leading to the disruption of several processes held responsible for metabolic health. 
important transducers of insulin-regulated signaling, possibly contributing to both protein and cell dysfunction (Grimsrud et al., 2007). 4-HNE has also been shown to initiate chronic adipose tissue inflammation via induction of cyclooxygenase-2 (COX) by p38 activation (Zarrouki et al., 2007). Furukawa and colleagues have shown that blocking NOX with apocynin resulted in decreased ROS production, improved adiponectin release and thus improved insulin sensitivity in obese mice (Furukawa et al., 2004). Finally, since the aging process is positively correlated with markers of oxidative stress (Harman, 1956, 1998, 2003), Findeisen and Bruemmer suggested that the adipose tissue is similarly affected. 3T3-L1 cells treated with L-buthionine-(S,R)-sulfoximine (BSO), an indirect inducer of oxidative stress, displayed no adipogenic differentiation, concomitant with transcriptional repression of E2F target genes (Findeisen et al., 2011).

Aging has also been shown to have a negative impact on the function of preadipocytes impairing tissue renewal. Some examples of preadipocyte impairment associated with aging include: decline in preadipocyte replication (Djian et al., 1983), decreased adipogenesis (Kirkland et al., 1990), lower levels of PPAR $\gamma$ and C/EBP $\alpha$ from aged human and rat adipocytes after exposure to differentiation cocktails (Karagiannides et al., 2001). A typical hallmark of aging is the accumulation of senescent cells and this has been observed in the preadipocyte pool from obese and also from elderly individuals (Minamino et al., 2009; Tchkonia et al., 2010). Altogether, aging itself can be regarded as a risk factor for adipose tissue dysfunction.

Despite the pathophysiological effects of oxidative stress on adipose tissue homeostasis, the presence of a sufficient amount of ROS is a prerequisite for adipogenesis, as described before, and therefore ROS clearance can be considered as another risk factor for adipose tissue dysfunction. In the following section we will discuss the roles of antioxidants in adipocytes and how they can exert both adverse and beneficial effects therein.

\section{Antioxidants in adipocyte dysfunction-associated metabolic diseases}

\section{Obesity, oxidative stress, and beneficial effects of antioxidants in animal studies}

Chronic obesity and T2D are associated with elevated levels of biomarkers of oxidative stress (e.g. lipid peroxidation end products and protein carbonylation) in the circulation, in WAT and in (hypertrophied) adipocytes (Furukawa et al., 2004; Jankovic et al., 2014; Chattopadhyay et al., 2015). As examples, plasma thiobarbituric acid reactive substance (TBARS) and 4-HNE protein adducts, two markers of lipid peroxidation, were significantly correlated with BMI and increased in obese with (mean BMI $41.8 \mathrm{~kg} / \mathrm{m}^{2}$ ) and without (mean BMI $38.3 \mathrm{~kg} / \mathrm{m}^{2}$ ) MetS compared to lean (mean BMI $22.5 \mathrm{~kg} / \mathrm{m}^{2}$ ) control individuals, respectively (Furukawa et al., 2004; Lubrano et al., 2015). Equivalent to the situation in humans, Furukawa et al. reported elevation of plasma TBARS levels in mice that were rendered obese either by feeding high caloric diets or where obesity developed spontaneously due to monoand polygenic gene mutations. These and others findings also indicated that systemic oxidative stress in obese mice is due to increased ROS production in the WAT (Furukawa et al., 2004; Houstis et al., 2006; Curtis et al., 2010). An obesity-associated and WAT-derived increase in oxidative stress has been suggested as a trigger of WAT dysfunction and to promote insulin resistance in metabolic organs (Rains and Jain, 2011), which eventually leads to the formation of MetS and T2D. In agreement with this concept, treatments with compounds that decrease ROS levels, either by inhibiting ROS formation (Furukawa et al., 2004), by inducing ROS-degrading antioxidant enzymes (Anderson et al., 2009), or by direct reduction of ROS (Anderson et al., 2009), were reported to improve insulin sensitivity as well as lipid and glucose homeostasis in animal models of diabetes. For example, in obese mice the NOX inhibitor apocynin decreased adipose tissue ROS levels, restored dysregulated adipokine secretion, and improved hyperlipidemia, diabetes and hepatic steatosis (Furukawa et al., 2004). Similarly, glutathione-S-transferase A4 is depleted in the WAT of obese mice, which results in increased protein carbonylation in adipocytes and impaired glucose and lipid homeostasis (Curtis et al., 2010). A mitochondrial-targeted antioxidant as well as overexpression of catalase (in skeletal muscle) preserved insulin sensitivity in mice that were fed a high-fat diet and had developed a diabetic phenotype under control conditions (Anderson et al., 2009).

\section{Adverse effects of antioxidants in human studies}

These findings derived from animal studies attributed a causal role for oxidative stress in the development of diabetes and led to clinical studies assessing the therapeutic and preventive potential of (dietary) antioxidants, e.g. 
vitamin $\mathrm{C}$ and $\mathrm{E}$, against metabolic disorders associated with obesity. Meta-analysis of 14 randomized controlled trials (RTCs) of vitamin C and E interventions revealed however, that none of the supplements improved fasting blood glucose or insulin levels in T2D patients (Akbar et al., 2011), a result that questioned the usefulness of high dose vitamin $\mathrm{C}$ and $\mathrm{E}$ supplementation for T2D. Similarly, the Supplementation en Vitamines et Minéraux Antioxydants (SU.VI.MAX) intervention trial with 5220 participants examined the effects of long-term ( 7.5 years) supplementation with a mixture of dietary antioxidants (vitamins $\mathrm{C}$ and $\mathrm{E}, \beta$-carotene, zinc and selenium) and found no difference in MetS incidence between the supplemented and the placebo group (Czernichow et al., 2009). This indicates that lower serum concentrations of some antioxidants (e.g. vitamin C, $\alpha$ - and $\beta$-carotene) in MetS subjects, as observed in a case-control assessment of participants from the Third NHANES (National Health and Nutrition Examination) study, are not causal for the development of MetS (Ford et al., 2003). An unexpected outcome of the SU.VI.MAX trial was the observation of an adverse serum lipid profile in the antioxidant supplementation group: mean serum TG concentrations were significantly higher in the supplemented group compared to placebo, and the prevalence of hypertriglyceridemia was higher in male but not in female recipients. Rather harmful effects of antioxidant supplements have also been suggested by a meta-analysis of 78 RTCs with 300000 participants, wherein supplementation with $\beta$-carotene as well as vitamin $\mathrm{E}$ was associated with higher all-cause mortality, while supplementations with other antioxidants [vitamin C, selenium (Se)] had no significant effect on all-cause mortality (Bjelakovic et al., 2013). A major constituent of some crucial antioxidant defense systems is the trace element Se, as it resides in the form of the mRNA-encoded amino acid selenocysteine in antioxidant selenoenzymes. Dietary Se compounds have successfully been used to alleviate oxidative stress-associated diseases, e.g. inflammatory bowel diseases (Speckmann and Steinbrenner, 2014), and for cancer prevention in humans and rodents (Steinbrenner et al., 2013). However, secondary analysis of the U.S. National Prevention of Cancer trial suggested that overdosing Se might increase the risk of T2D (Stranges et al., 2007; Steinbrenner et al., 2011). Plasma levels of the selenium transport protein selenoprotein $\mathrm{P}(\mathrm{SeP})$ are positively associated with blood glucose levels (Steinbrenner, 2013), and it was proposed that this relationship reflects the transcriptional and hormonal regulation of hepatic SeP expression by e.g. glucose, insulin and glucocorticoids, similar to the regulation of gluconeogenic enzymes
(Speckmann et al., 2008). However, Se compounds and selenoproteins have been shown to interfere with insulin-regulated carbohydrate and lipid metabolism (Steinbrenner, 2013), hence increased Se status might causally contribute to the development of hyperlipidemia, as observed in cross-sectional studies like the recently evaluated NHANES data from 2011 to 2012 (Christensen et al., 2015). A recent cross-sectional study showed that even Se intake levels considered as adequate were associated with higher T2D prevalence compared to sub-optimal Se intake in a Chinese population (Wei et al., 2015). Likewise, a trial conducted with T2D patients reported worsened hyperglycemia in those subjects who had received Se in form of daily doses of $200 \mu \mathrm{g}$ sodium selenite for 3 months compared to the placebo group (Faghihi et al., 2014). Interferences of Se and selenoproteins with the insulin-regulated carbohydrate and lipid metabolism are discussed in detail in a recent review (Steinbrenner, 2013), wherein GPx-1 and SeP are highlighted as mediators of adverse effects of Se regarding insulin sensitivity. Risk of major cardiovascular diseases, which often arise in diabetic patients, was not modified by supplementation of vitamins and antioxidants (vitamin A, B6, B12, C, D, E, $\beta$-carotene, folic acid, Se), as revealed by meta-analysis of 50 RTCs with a total of 300000 participants (Myung et al., 2013). Altogether these epidemiologic data imply that well-nourished populations with no severe nutrient deficiencies do not benefit from (over)supplementation of dietary antioxidants with respect to the prevention or treatment of MetS or T2D.

\section{Adverse effects of antioxidants in animal and in vitro studies}

Analogously, undesired effects of excess antioxidant supplementation were revealed by findings from numerous animal and in vitro studies (outlined above) demonstrating that ROS are required for insulin signaling (Goldstein et al., 2005) and that in fact ROS quenching can cause insulin resistance and diabetes-like phenotypes in rodents and pigs. For example, the above-mentioned link between Se and T2D from human studies is supported by a number of animal experiments wherein supranutritional intake of Se as well as overexpression of certain selenoproteins like GPx-1 and SeP led to insulin resistance and/ or diabetes-like phenotypes in rodents and pigs (summarized in Zhou et al., 2013). In the following section, we will review the available literature derived from animal and in vitro studies regarding effects of dietary antioxidants on the functions of WAT and adipocytes in the context 
of metabolic disorders. It is intriguing to speculate that high Se and/or selenoprotein levels in adipose tissue may adversely affect adipogenesis and lipid storage capacity. For the majority of selenoproteins their possible contributions to adipogenesis remain to be determined, with the exceptions of SeP and selenoprotein S: while physiological levels of SeP are required for in vitro adipogenesis of 3T3-L1 cells (Zhang and Chen, 2011), forced expression of selenoprotein S prevents differentiation to adipocytes (Kim and Kim, 2013). Hampering ROS production in preadipocyte cell cultures inhibited adipocyte differentiation; therefore, related effects were expected to occur upon antioxidant supplementation. In line with this, vitamin $\mathrm{C}$ dose-dependently inhibited the differentiation of 3T3-L1 and OP9 cells to adipocytes (Rahman et al., 2014). Interestingly, this work indicated that the vitamin C effect did not depend on its antioxidant properties but instead involved inhibition of adenylate cyclases to reduce intracellular cAMP levels. Another possible explanation stems from a mechanistic study showing that vitamin $C$ is a specific co-factor of Tet enzymes (Yin et al., 2013), suggesting that vitamin $\mathrm{C}$ is involved in the epigenetic rearrangement that occurs during adipogenesis. Naturally occurring vitamin $\mathrm{E}$ is a mixture of structurally similar compounds, tocopherols and tocotrienols, with different extents of vitamin E activity. Rodent studies have shown that $\alpha$-tocotrienol and $\gamma$-tocotrienol accumulate in adipose tissue (Ikeda et al., 2001), and the latter decreased body fat levels in adrenalectomized rats (Ima-Nirwana and Suhaniza, 2004). This anti-adipogenic effect was confirmed in vitro for 3T3-L1 cells, where the two vitamin E isoforms suppressed the induction of adipogenic genes during adipogenesis (Uto-Kondo et al., 2009). $\gamma$-Tocotrienol inhibited the insulin-dependent phosphorylation of Akt but not of ERK1/2, indicating that the antioxidant activity of $\gamma$-tocotrienol interferes with superoxide released by NOX4 during insulin signaling. The Nrf2-inducer sulforaphane inhibited adipogenesis in vitro, and furthermore, constitutive activation of Nrf2 suppressed adipogenesis and induced insulin resistance in Lep ${ }^{o b / o b}$ mice in vivo (Xu et al., 2012). The use of anti-diabetogenic compounds as well as increased intake of antioxidants in the context of a positive energy balance may, therefore, have the undesirable effect of ectopic fat accumulation.

\section{Conclusions}

We propose a model of balanced ROS levels that are required for proper functioning of the WAT (Figure 4). In this model, both too low and too high levels of ROS impede

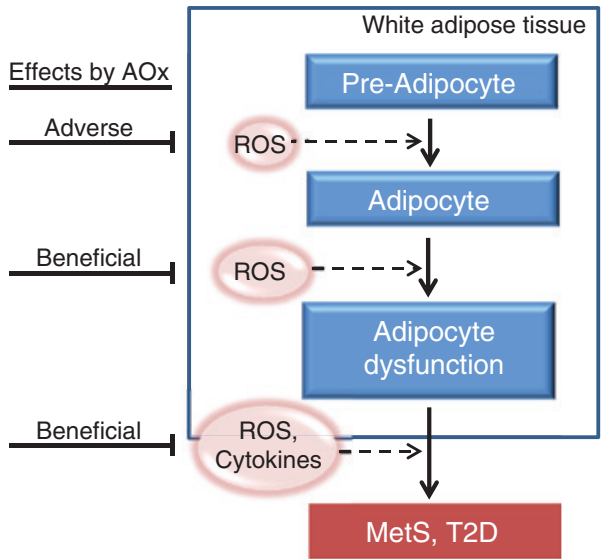

Figure 4: Adverse and beneficial effects of antioxidants/ROS in the context of adipocyte function/dysfunction.

ROS formation is required for differentiation of preadipocytes to adipocytes. Increasing ROS levels trigger adipocyte dysfunction, which can result in oxidative stress and inflammation in and outside the WAT, contributing to the development of MetS and T2D. Antioxidants can interfere with ROS levels under all conditions and thus exert both beneficial and adverse effects, depending on the type, dose, and target of the antioxidant, as well as on the metabolic stage.

with differentiation of preadipocytes and cellular functions of mature adipocytes. In manifest T2D, increased ROS levels in the WAT result in reduced adipogenesis, increased lipolysis and macrophage infiltration, which exacerbate adipose tissue dysfunction, whereby interventions to reduce ROS levels may be beneficial in the management of the disease and its associated complications. However, the use of antioxidant supplements or anti-adipogenic compounds that interfere with insulin-mediated signaling may be unfavorable in the prevention of MetS and T2D, particularly during excess nutrient intake that requires appropriate expansion of WAT.

\section{References}

Ahima, R.S. (2009). Connecting obesity, aging and diabetes. Nat. Med. 15, 996-997.

Akbar, S., Bellary, S., and Griffiths, H.R. (2011). Dietary antioxidant interventions in type 2 diabetes patients: a meta-analysis. Br. J. Diabetes Vas. Dis. 11, 62-68.

Anderson, E.J., Lustig, M.E., Boyle, K.E., Woodlief, T.L., Kane, D.A., Lin, C.T., Price, J.W. 3rd, Kang, L., Rabinovitch, P.S., Szeto, H.H., et al. (2009). Mitochondrial $\mathrm{H}_{2} \mathrm{O}_{2}$ emission and cellular redox state link excess fat intake to insulin resistance in both rodents and humans. J. Clin. Invest. 119, 573-581.

Barja, G. (2014). The mitochondrial free radical theory of aging. Prog. Mol. Biol. Transl. Sci. 127, 1-27.

Barroso, I., Gurnell, M., Crowley, V.E., Agostini, M., Schwabe, J.W., Soos, M.A., Maslen, G.L., Williams, T.D., Lewis, H., 
Schafer, A.J., et al. (1999). Dominant negative mutations in human PPARgamma associated with severe insulin resistance, diabetes mellitus and hypertension. Nature 402, 880-883.

Bedard, K. and Krause, K.H. (2007). The NOX family of ROS-generating NADPH oxidases: physiology and pathophysiology. Physiol. Rev. 87, 245-313.

Bjelakovic, G., Nikolova, D., and Gluud, C. (2013). Antioxidant supplements to prevent mortality. J. Am. Med. Assoc. 310, 1178-1179.

Bollineni, R.C., Fedorova, M., Blüher, M., and Hoffmann, R. (2014). Carbonylated plasma proteins as potential biomarkers of obesity induced type 2 diabetes mellitus. J. Proteome. Res. 13, 5081-5093.

Brand, M.D. (2010). The sites and topology of mitochondrial superoxide production. Exp. Gerontol. 45, 466-472.

Bremer, A.A. and Jialal, I. (2013). Adipose tissue dysfunction in nascent metabolic syndrome. J. Obes. 2013, 393192.

Cancello, R., Henegar, C., Viguerie, N., Taleb, S., Poitou, C., Rouault, C., Coupaye, M., Pelloux, V., Hugol, D., Bouillot, J.L., et al. (2005). Reduction of macrophage infiltration and chemoattractant gene expression changes in white adipose tissue of morbidly obese subjects after surgery-induced weight loss. Diabetes 54, 2277-2286.

Carnevalli, L.S., Masuda, K., Frigerio, F., Le Bacquer, O., Um, S.H., Gandin, V., Topisirovic, I., Sonenberg, N., Thomas, G., and Kozma, S.C. (2010). S6K1 plays a critical role in early adipocyte differentiation. Dev. Cell 18, 763-774.

Carriere, A., Fernandez, Y., Rigoulet, M., Penicaud, L., and Casteilla, L. (2003). Inhibition of preadipocyte proliferation by mitochondrial reactive oxygen species. FEBS Lett. 550, 163-167.

Castro, J.P., Ott, C., Jung, T., Grune, T., and Almeida, H. (2012). Carbonylation of the cytoskeletal protein actin leads to aggregate formation. Free Radic. Biol. Med. 53, 916-925.

Chattopadhyay, M., Khemka, V.K., Chatterjee, G., Ganguly, A., Mukhopadhyay, S., and Chakrabarti, S. (2015). Enhanced ROS production and oxidative damage in subcutaneous white adipose tissue mitochondria in obese and type 2 diabetes subjects. Mol. Cell Biochem. 399, 95-103.

Cho, S.H., Lee, C.H., Ahn, Y., Kim, H., Kim, H., Ahn, C.Y., Yang, K.S., and Lee, S.R. (2004). Redox regulation of PTEN and protein tyrosine phosphatases in $\mathrm{H}_{2} \mathrm{O}_{2}$ mediated cell signaling. FEBS Lett. 560, 7-13.

Christensen, K., Werner, M., and Malecki, K. (2015). Serum selenium and lipid levels: Associations observed in the National Health and Nutrition Examination Survey (NHANES) 2011-2012. Environ. Res. 140, 76-84.

Cotillard, A., Poitou, C., Torcivia, A., Bouillot, J.L., Dietrich, A., Kloting, N., Grégoire, C., Lolmede, K., Blüher, M., and Clement, K. (2014). Adipocyte size threshold matters: link with risk of type 2 diabetes and improved insulin resistance after gastric bypass. J. Clin. Endocrinol. Metab. 99, E1466-1470.

Curtis, J.M., Grimsrud, P.A., Wright, W.S., Xu, X., Foncea, R.E., Graham, D.W., Brestoff, J.R., Wiczer, B.M., Ilkayeva, O., Cianflone, K., et al. (2010). Downregulation of adipose glutathione S-transferase A4 leads to increased protein carbonylation, oxidative stress, and mitochondrial dysfunction. Diabetes 59, 1132-1142.

Czernichow, S., Vergnaud, A.C., Galan, P., Arnaud, J., Favier, A., Faure, H., Huxley, R., Hercberg, S., and Ahluwalia, N. (2009). Effects of long-term antioxidant supplementation and associa- tion of serum antioxidant concentrations with risk of metabolic syndrome in adults. Am. J. Clin. Nutr. 90, 329-335.

Dalle-Donne, I., Giustarini, D., Colombo, R., Rossi, R., and Milzani, A. (2003). Protein carbonylation in human diseases. Trends Mol. Med. 9, 169-176.

Dasuri, K., Zhang, L., Ebenezer, P., Fernandez-Kim, S.O., Bruce-Keller, A.J., Szweda, L.I., and Keller, J.N. (2011). Proteasome alterations during adipose differentiation and aging: links to impaired adipocyte differentiation and development of oxidative stress. Free Radic. Biol. Med. 51, 1727-1735.

Davies, K.J. and Shringarpure, R. (2006). Preferential degradation of oxidized proteins by the $20 \mathrm{~S}$ proteasome may be inhibited in aging and in inflammatory neuromuscular diseases. Neurology 66 (Suppl 1), S93-96.

De Pauw, A., Tejerina, S., Raes, M., Keijer, J., and Arnould, T. (2009). Mitochondrial (dys)function in adipocyte (de)differentiation and systemic metabolic alterations. Am. J. Pathol. 175, 927-939.

Diaz-Ruiz, A., Guzman-Ruiz, R., Moreno, N.R., Garcia-Rios, A., Delgado-Casado, N., Membrives, A., Túnez, I., El Bekay, R., Fernández-Real, J.M., Tovar, S., et al. (2015). Proteasome dysfunction associated to oxidative stress and proteotoxicity in adipocytes compromises insulin sensitivity in human obesity. Antioxid. Redox. Signal. 23, 597-612.

Dikalov, S. (2011). Cross talk between mitochondria and NADPH oxidases. Free Radic. Biol. Med. 51, 1289-1301.

Djian, P., Roncari, A.K., and Hollenberg, C.H. (1983). Influence of anatomic site and age on the replication and differentiation of rat adipocyte precursors in culture. J. Clin. Invest. 72, $1200-1208$.

Drong, A.W., Lindgren, C.M., and McCarthy, M.I. (2012). The genetic and epigenetic basis of type 2 diabetes and obesity. Clin. Pharmacol. Ther. 92, 707-715.

Faghihi, T., Radfar, M., Barmal, M., Amini, P., Qorbani, M., Abdollahi, M., and Larijani, B. (2014). A randomized, placebocontrolled trial of selenium supplementation in patients with type 2 diabetes: effects on glucose homeostasis, oxidative stress, and lipid profile. Am. J. Ther. 21, 491-495.

Findeisen, H.M., Pearson, K.J., Gizard, F., Zhao, Y., Qing, H., Jones, K.L., Cohn, D., Heywood, E.B., de Cabo, R., and Bruemmer, D. (2011). Oxidative stress accumulates in adipose tissue during aging and inhibits adipogenesis. PLoS One 6, e18532.

Fisher-Wellman, K.H. and Neufer, P.D. (2012). Linking mitochondrial bioenergetics to insulin resistance via redox biology. Trends Endocrinol. Metab. 23, 142-153.

Ford, E.S., Mokdad, A.H., Giles, W.H., and Brown, D.W. (2003). The metabolic syndrome and antioxidant concentrations: findings from the Third National Health and Nutrition Examination Survey. Diabetes 52, 2346-2352.

Frohnert, B.I. and Bernlohr, D.A. (2013). Protein carbonylation, mitochondrial dysfunction, and insulin resistance. Adv. Nutrition 4, 157-163.

Fujiki, K., Kano, F., Shiota, K., and Murata, M. (2009). Expression of the peroxisome proliferator activated receptor gamma gene is repressed by DNA methylation in visceral adipose tissue of mouse models of diabetes. BMC Biol. 7, 38.

Fujiki, K., Shinoda, A., Kano, F., Sato, R., Shirahige, K., and Murata, M. (2013). PPAR $\gamma$-induced PARylation promotes local DNA demethylation by production of 5-hydroxymethylcytosine. Nat. Commun. 4, 2262. 
Furukawa, S., Fujita, T., Shimabukuro, M., Iwaki, M., Yamada, Y., Nakajima, Y., Nakayama, O., Makishima, M., Matsuda, M., and Shimomura, I. (2004). Increased oxidative stress in obesity and its impact on metabolic syndrome. J. Clin. Invest. 114, 1752-1761.

Gagnon, A., Lau, S., and Sorisky, A. (2001). Rapamycin-sensitive phase of 3T3-L1 preadipocyte differentiation after clonal expansion. J. Cell Physiol. 189, 14-22.

Gandotra, S., Le Dour, C., Bottomley, W., Cervera, P., Giral, P., Reznik, Y., Charpentier, G., Auclair, M., Delépine, M., Barroso, I., et al. (2011). Perilipin deficiency and autosomal dominant partial lipodystrophy. N. Engl. J. Med. 364, 740-748.

Goldstein, B.J., Mahadev, K., and Wu, X. (2005). Redox paradox: insulin action is facilitated by insulin-stimulated reactive oxygen species with multiple potential signaling targets. Diabetes 54, 311-321.

Grimsrud, P.A., Picklo, M.J., Sr., Griffin, T.J., and Bernlohr, D.A. (2007). Carbonylation of adipose proteins in obesity and insulin resistance: identification of adipocyte fatty acid-binding protein as a cellular target of 4-hydroxynonenal. Mol. Cell Proteomics 6, 624-637.

Grune, T., Reinheckel, T., Joshi, M., and Davies, K.J. (1995). Proteolysis in cultured liver epithelial cells during oxidative stress. Role of the multicatalytic proteinase complex, proteasome. J. Biol. Chem. 270, 2344-2351.

Grune, T., Reinheckel, T., and Davies, K.J. (1996). Degradation of oxidized proteins in $\mathrm{K} 562$ human hematopoietic cells by proteasome. J. Biol. Chem. 271, 15504-15509.

Grune, T., Reinheckel, T., and Davies, K.J. (1997). Degradation of oxidized proteins in mammalian cells. FASEB J. 11, 526-534.

Grune, T., Merker, K., Sandig, G., and Davies, K.J. (2003). Selective degradation of oxidatively modified protein substrates by the proteasome. Biochem. Biophys. Res. Commun. 305, 709-718.

Guilherme, A., Virbasius, J.V., Puri, V., and Czech, M.P. (2008). Adipocyte dysfunctions linking obesity to insulin resistance and type 2 diabetes. Nat. Rev. Mol. Cell Biol. 9, 367-377.

Halliwell, B. (2006). Reactive species and antioxidants. Redox biology is a fundamental theme of aerobic life. Plant Physiol. 141, 312-322.

Han, C.Y., Umemoto, T., Omer, M., Den Hartigh, L.J., Chiba, T., LeBoeuf, R., Buller, C.L., Sweet, I.R., Pennathur, S., Abel, E.D., et al. (2012). NADPH oxidase-derived reactive oxygen species increases expression of monocyte chemotactic factor genes in cultured adipocytes. J. Biol. Chem. 287, 10379-10393.

Harman, D. (1956). Aging: a theory based on free radical and radiation chemistry. J. Gerontol. 11, 298-300.

Harman, D. (1998). Aging and oxidative stress. J. Int. Fed. Clin. Chem. 10, 24-27.

Harman, D. (2003). The free radical theory of aging. Antioxid. Redox. Signal 5, 557-561.

Hemming, S., Cakouros, D., Isenmann, S., Cooper, L., Menicanin, D., Zannettino, A., and Gronthos, S. (2014). EZH2 and KDM6A act as an epigenetic switch to regulate mesenchymal stem cell lineage specification. Stem. Cells 32, 802-815.

Hensley, K., Robinson, K.A., Gabbita, S.P., Salsman, S., and Floyd, R.A. (2000). Reactive oxygen species, cell signaling, and cell injury. Free Radic. Biol. Med. 28, 1456-1462.

Höhn, A., Jung, T., and Grune, T. (2014). Pathophysiological importance of aggregated damaged proteins. Free Radic. Biol. Med. $71,70-89$.
Hohn, A., Konig, J., and Grune, T. (2013). Protein oxidation in aging and the removal of oxidized proteins. J. Proteomics. 92, 132-159.

Houstis, N., Rosen, E.D., and Lander, E.S. (2006). Reactive oxygen species have a causal role in multiple forms of insulin resistance. Nature 440, 944-948.

Ikeda, S., Toyoshima, K., and Yamashita, K. (2001). Dietary sesame seeds elevate $\mathrm{a}$ - and g-tocotrienol concentrations in skin and adipose tissue of rats fed the tocotrienol-rich fraction extracted from palm oil. J. Nutr. 131, 2892-2897.

Ima-Nirwana, S. and Suhaniza, S. (2004). Effects of tocopherols and tocotrienols on body composition and bone calcium content in adrenalectomized rats replaced with dexamethasone. J. Med. Food 7, 45-51.

Imhoff, B.R. and Hansen, J.M. (2011). Differential redox potential profiles during adipogenesis and osteogenesis. Cell Mol. Biol. Lett. 16, 149-161.

Iwakami, S., Misu, H., Takeda, T., Sugimori, M., Matsugo, S., Kaneko, S., and Takamura, T. (2011). Concentration-dependent dual effects of hydrogen peroxide on insulin signal transduction in H4IIEC hepatocytes. PLoS One 6, e27401.

Jankovic, A., Korac, A., Srdic-Galic, B., Buzadzic, B., Otasevic, V., Stancic, A., Vucetic, M., Markelic, M., Velickovic, K., Golic, I., et al. (2014). Differences in the redox status of human visceral and subcutaneous adipose tissues-relationships to obesity and metabolic risk. Metabolism 63, 661-671.

Jung, T., Catalgol, B., and Grune, T. (2009). The proteasomal system. Mol. Aspects Med. 30, 191-296.

Kahn, S.E., Hull, R.L., and Utzschneider, K.M. (2006). Mechanisms linking obesity to insulin resistance and type 2 diabetes. Nature 444, 840-846.

Karagiannides, I., Tchkonia, T., Dobson, D.E., Steppan, C.M., Cummins, P., Chan, G., Salvatori, K., Hadzopoulou-Cladaras, M., and Kirkland, J.L. (2001). Altered expression of C/EBP family members results in decreased adipogenesis with aging. Am. J. Physiol. Regul. Integr. Comp. Physiol. 280, R1772-1780.

Kastle, M., Reeg, S., Rogowska-Wrzesinska, A., and Grune, T. (2012). Chaperones, but not oxidized proteins, are ubiquitinated after oxidative stress. Free Radic. Biol. Med. 53, 1468-1477.

Kim, J.E. and Chen, J. (2004). regulation of peroxisome proliferatoractivated receptor-gamma activity by mammalian target of rapamycin and amino acids in adipogenesis. Diabetes 53 , 2748-2756.

Kim, C.Y. and Kim, K.H. (2013). Dexamethasone-induced selenoprotein $\mathrm{S}$ degradation is required for adipogenesis. J. Lipid. Res. 54, 2069-2082.

Kirkland, J.L., Hollenberg, C.H., and Gillon, W.S. (1990). Age, anatomic site, and the replication and differentiation of adipocyte precursors. Am. J. Physiol. 258, C206-210.

Kirkland, J.L., Hollenberg, C.H., Kindler, S., and Gillon, W.S. (1994). Effects of age and anatomic site on preadipocyte number in rat fat depots. J. Gerontol. 49, B31-35.

Kirkland, J.L., Tchkonia, T., Pirtskhalava, T., Han, J., and Karagiannides, I. (2002). Adipogenesis and aging: does aging make fat go MAD? Exp. Gerontol. 37, 757-767.

Konige, M., Wang, H., and Sztalryd, C. (2014). Role of adipose specific lipid droplet proteins in maintaining whole body energy homeostasis. Biochim. Biophys. Acta 1842, 393-401.

Kono, T., Robinson, F.W., Blevins, T.L., and Ezaki, O. (1982). Evidence that translocation of the glucose transport activity is the major 
mechanism of insulin action on glucose transport in fat cells. J. Biol. Chem. 257, 10942-10947.

Lau, D.C., Dhillon, B., Yan, H., Szmitko, P.E., and Verma, S. (2005). Adipokines: molecular links between obesity and atheroslcerosis. Am. J. Physiol. Heart Circ. Physiol. 288, H2031-2041.

Le Lay, S., Simard, G., Martinez, M.C., and Andriantsitohaina, R. (2014). Oxidative stress and metabolic pathologies: from an adipocentric point of view. Oxid. Med. Cell Longev. 2014, 908539.

LeBlanc, S.E., Konda, S., Wu, Q., Hu, Y.J., Oslowski, C.M., Sif, S., and Imbalzano, A.N. (2012). Protein arginine methyltransferase 5 (Prmt5) promotes gene expression of peroxisome proliferatoractivated receptor g2 (PPARg2) and its target genes during adipogenesis. Mol. Endocrinol. 26, 583-597.

Lee, H., Lee, Y.J., Choi, H., Ko, E.H., and Kim, J.W. (2009). Reactive oxygen species facilitate adipocyte differentiation by accelerating mitotic clonal expansion. J. Biol. Chem. 284, 10601-10609.

Lee, K.H., Ju, U.I., Song, J.Y., and Chun, Y.S. (2014). The histone demethylase PHF2 promotes fat cell differentiation as an epigenetic activator of both C/EBPa and C/EBPd. Mol. Cells 37, 734-741.

Levine, R.L. and Stadtman, E.R. (2001). Oxidative modification of proteins during aging. Exp. Gerontol. 36, 1495-1502.

Little, S.A. and de Haen, C. (1980). Effects of hydrogen peroxide on basal and hormone-stimulated lipolysis in perifused rat fat cells in relation to the mechanism of action of insulin. J. Biol. Chem. 255, 10888-10895.

Loh, K., Deng, H., Fukushima, A., Cai, X., Boivin, B., Galic, S., Bruce, C., Shields, B.J., Skiba, B., Ooms, L.M., et al. (2009). Reactive oxygen species enhance insulin sensitivity. Cell Metab. 10, 260-272.

Lubrano, C., Valacchi, G., Specchia, P., Gnessi, L., Rubanenko, E.P., Shuginina, E.A., Trukhanov, A.I., Korkina, L.G., and De Luca, C. (2015). Integrated haematological profiles of redox status, lipid, and inflammatory protein biomarkers in benign obesity and unhealthy obesity with metabolic syndrome. Oxid. Med. Cell Longev. 2015, 490613.

Lundgren, M., Svensson, M., Lindmark, S., Renstrom, F., Ruge, T., and Eriksson, J.W. (2007). Fat cell enlargement is an independent marker of insulin resistance and 'hyperleptinaemia'. Diabetologia 50, 625-633.

Mackall, J.C., Student, A.K., Polakis, S.E., and Lane, M.D. (1976). Induction of lipogenesis during differentiation in a "preadipocyte" cell line. J. Biol. Chem. 251, 6462-6464.

Mahadev, K., Wu, X., Zilbering, A., Zhu, L., Lawrence, J.T., and Goldstein, B.J. (2001). Hydrogen peroxide generated during cellular insulin stimulation is integral to activation of the distal insulin signaling cascade in 3T3-L1 adipocytes. J. Biol. Chem. 276, 48662-48669.

Mahadev, K., Motoshima, H., Wu, X., Ruddy, J.M., Arnold, R.S., Cheng, G., Lambeth, J.D., and Goldstein, B.J. (2004). The NAD(P)H oxidase homolog Nox4 modulates insulin-stimulated generation of $\mathrm{H} 2 \mathrm{O} 2$ and plays an integral role in insulin signal transduction. Mol. Cell Biol. 24, 1844-1854.

May, J.M. and de Haen, C. (1979). Insulin-stimulated intracellular hydrogen peroxide production in rat epididymal fat cells. J. Biol. Chem. 254, 2214-2220.

Minamino, T., Orimo, M., Shimizu, I., Kunieda, T., Yokoyama, M., Ito, T., Nojima, A., Nabetani, A., Oike, Y., Matsubara, H., et al. (2009). A crucial role for adipose tissue p53 in the regulation of insulin resistance. Nat. Med. 15, 1082-1087.
Murdolo, G., Piroddi, M., Luchetti, F., Tortoioli, C., Canonico, B., Zerbinati, C., Galli, F., and Iuliano, L. (2013). Oxidative stress and lipid peroxidation by-products at the crossroad between adipose organ dysregulation and obesity-linked insulin resistance. Biochimie 95, 585-594.

Myung, S.K., Ju, W., Cho, B., Oh, S.W., Park, S.M., Koo, B.K., Park B.J., and Korean Meta-Analysis Study, G. (2013). Efficacy of vitamin and antioxidant supplements in prevention of cardiovascular disease: systematic review and meta-analysis of randomised controlled trials. Br. Med. J. 346, f10.

Nilsson, E., Jansson, P.A., Perfilyev, A., Volkov, P., Pedersen, M., Svensson, M.K., Poulsen, P., Ribel-Madsen, R., Pedersen, N.L., Almgren, P., et al. (2014). Altered DNA methylation and differential expression of genes influencing metabolism and inflammation in adipose tissue from subjects with type 2 diabetes. Diabetes 63, 2962-2976.

Nyström, T. (2005). Role of oxidative carbonylation in protein quality control and senescence. EMBO J. 24, 1311-1317.

Park, H.T., Lee, E.S., Cheon, Y.P., Lee, D.R., Yang, K.S., Kim, Y.T., Hur, J.Y., Kim, S.H., Lee, K.W., and Kim, T. (2012). The relationship between fat depot-specific preadipocyte differentiation and metabolic syndrome in obese women. Clin. Endocrinol. (Oxf) $76,59-66$.

Peng, X.D., Xu, P.Z., Chen, M.L., Hahn-Windgassen, A., Skeen, J., Jacobs, J., Sundararajan, D., Chen, W.S., Crawford, S.E., Coleman, K.G., et al. (2003). Dwarfism, impaired skin development, skeletal muscle atrophy, delayed bone development, and impeded adipogenesis in mice lacking Akt1 and Akt2. Genes. Dev. 17, 1352-1365.

Pietilainen, K.H., Naukkarinen, J., Rissanen, A., Saharinen, J., Ellonen, P., Keranen, H., Suomalainen, A., Götz, A., Suortti, T., Yki-Järvinen, H., et al. (2008). Global transcript profiles of fat in monozygotic twins discordant for BMI: pathways behind acquired obesity. PLoS Med. 5, e51.

Pittenger, M.F., Mackay, A.M., Beck, S.C., Jaiswal, R.K., Douglas, R., Mosca, J.D., Moorman, M.A., Simonetti, D.W., Craig, S., and Marshak, D.R. (1999). Multilineage potential of adult human mesenchymal stem cells. Science 284, 143-147.

Poulos, S.P., Dodson, M.V., and Hausman, G.J. (2010). Cell line models for differentiation: preadipocytes and adipocytes. Exp. Biol. Med. (Maywood) 235, 1185-1193.

Rahman, F., Al Frouh, F., Bordignon, B., Fraterno, M., Landrier, J.F., Peiretti, F., and Fontes, M. (2014). Ascorbic acid is a dosedependent inhibitor of adipocyte differentiation, probably by reducing CAMP pool. Front Cell Dev. Biol. 2, 29.

Rains, J.L. and Jain, S.K. (2011). Oxidative stress, insulin signaling, and diabetes. Free Radic. Biol. Med. 50, 567-575.

Reinheckel, T., Sitte, N., Ullrich, O., Kuckelkorn, U., Davies, K.J., and Grune, T. (1998). Comparative resistance of the 20S and 26S proteasome to oxidative stress. Biochem. J. 335, 637-642.

Rigoulet, M., Yoboue, E.D., and Devin, A. (2011). Mitochondrial ROS generation and its regulation: mechanisms involved in $\mathrm{H}(2) \mathrm{O}(2)$ signaling. Antioxid. Redox. Signal. 14, 459-468.

Rosen, E.D. and MacDougald, O.A. (2006). Adipocyte differentiation from the inside out. Nat. Rev. Mol. Cell Biol. 7, 885-896.

Rudich, A., Kozlovsky, N., Potashnik, R., and Bashan, N. (1997). Oxidant stress reduces insulin responsiveness in 3T3-L1 adipocytes. Am. J. Physiol. 272, E935-940.

Ryden, M., Arvidsson, E., Blomqvist, L., Perbeck, L., Dicker, A., and Arner, P. (2004). Targets for TNF-alpha-induced lipolysis 
in human adipocytes. Biochem. Biophys. Res. Commun. 318, 168-175.

Sandra, A. and Fyler, D.J. (1981). Effect of liposome-adipocyte interaction on hexose uptake and insulin action. Am. J. Physiol. 241, E281-290.

Scherz-Shouval, R., Shvets, E., Fass, E., Shorer, H., Gil, L., and Elazar, Z. (2007). Reactive oxygen species are essential for autophagy and specifically regulate the activity of Atg4. EMBO J. 26, 1749-1760.

Schroder, K., Wandzioch, K., Helmcke, I., and Brandes, R.P. (2009). Nox 4 acts as a switch between differentiation and proliferation in preadipocytes. Arterioscler. Thromb. Vasc. Biol. 29, 239-245.

Siersbaek, R., Nielsen, R., John, S., Sung, M.H., Baek, S., Loft, A., Hager, G.L., and Mandrup, S. (2011). Extensive chromatin remodelling and establishment of transcription factor 'hotspots' during early adipogenesis. EMBO J. 30, 1459-1472.

Sies, H. (2014). Role of metabolic H2O2 generation: redox signaling and oxidative stress. J. Biol. Chem. 289, 8735-8741.

Sies, H. (2015). Oxidative stress: a concept in redox biology and medicine. Redox. Biol. 4, 180-183.

Speckmann, B. and Steinbrenner, H. (2014). Selenium and selenoproteins in inflammatory bowel diseases and experimental colitis. Inflamm. Bowel. Dis. 20, 1110-1119.

Speckmann, B., Walter, P.L., Alili, L., Reinehr, R., Sies, H., Klotz, L.O., and Steinbrenner, H. (2008). Selenoprotein P expression is controlled through interaction of the coactivator PGC-1alpha with Fox01a and hepatocyte nuclear factor 4 alpha transcription factors. Hepatology 48, 1998-2006.

Stadtman, E.R. and Levine, R.L. (2000). Protein oxidation. Ann. NY Acad. Sci. 899, 191-208.

Steinbrenner, H. (2013). Interference of selenium and selenoproteins with the insulin-regulated carbohydrate and lipid metabolism. Free Radic. Biol. Med. 65, 1538-1547.

Steinbrenner, H., Speckmann, B., Pinto, A., and Sies, H. (2011). High selenium intake and increased diabetes risk: experimental evidence for interplay between selenium and carbohydrate metabolism. J. Clin. Biochem. Nutr. 48, 40-45.

Steinbrenner, H., Speckmann, B., and Sies, H. (2013). Toward understanding success and failures in the use of selenium for cancer prevention. Antioxid. Redox. Signal. 19, 181-191.

Stern, J.S., Batchelor, B.R., Hollander, N., Cohn, C.K., and Hirsch, J. (1972). Adipose-cell size and immunoreactive insulin levels in obese and normal-weight adults. Lancet 2, 948-951.

Stranges, S., Marshall, J.R., Natarajan, R., Donahue, R.P., Trevisan, M., Combs, G.F., Cappuccio, F.P., Ceriello, A., and Reid, M.E. (2007). Effects of long-term selenium supplementation on the incidence of type 2 diabetes: a randomized trial. Ann. Intern. Med. 147, 217-223.

Takada, H., Saito, Y., Mituyama, T., Wei, Z., Yoshihara, E., Jacinto, S., Downes, M., Evans, R.M., and Kida, Y.S. (2014). Methylome, transcriptome, and PPAR(gamma) cistrome analyses reveal two epigenetic transitions in fat cells. Epigenetics 9, 1195-1206.

Tamori, Y., Masugi, J., Nishino, N., and Kasuga, M. (2002). Role of peroxisome proliferator-activated receptor-gamma in maintenance of the characteristics of mature 3T3-L1 adipocytes. Diabetes 51, 2045-2055.

Tchkonia, T., Morbeck, D.E., Von Zglinicki, T., Van Deursen, J., Lustgarten, J., Scrable, H., Khosla, S., Jensen, M.D., and Kirkland, J.L. (2010). Fat tissue, aging, and cellular senescence. Aging Cell 9, 667-684.
Tormos, K.V., Anso, E., Hamanaka, R.B., Eisenbart, J., Joseph, J., Kalyanaraman, B., and Chandel, N.S. (2011). Mitochondrial complex III ROS regulate adipocyte differentiation. Cell Metab. 14, 537-544.

Ullrich, O., Reinheckel, T., Sitte, N., Hass, R., Grune, T., and Davies, K.J. (1999). Poly-ADP ribose polymerase activates nuclear proteasome to degrade oxidatively damaged histones. Proc. Natl. Acad. Sci. USA 96, 6223-6228.

Um, S.H., Frigerio, F., Watanabe, M., Picard, F., Joaquin, M., Sticker, M., Fumagalli, S., Allegrini, P.R., Kozma, S.C., Auwerx, J., et al. (2004). Absence of S6K1 protects against age- and dietinduced obesity while enhancing insulin sensitivity. Nature 431, 200-205.

Uto-Kondo, H., Ohmori, R., Kiyose, C., Kishimoto, Y., Saito, H., Igarashi, O., and Kondo, K. (2009). Tocotrienol suppresses adipocyte differentiation and Akt phosphorylation in 3T3-L1 preadipocytes. J. Nutr. 139, 51-57.

Valerio, A., Cardile, A., Cozzi, V., Bracale, R., Tedesco, L., Pisconti, A., Palomba, L., Cantoni, O., Clementi, E., Moncada, S., et al. (2006). TNF-alpha downregulates eNOS expression and mitochondrial biogenesis in fat and muscle of obese rodents. J. Clin. Invest. 116, 2791-2798.

Vigouroux, C., Caron-Debarle, M., Le Dour, C., Magre, J., and Capeau, J. (2011). Molecular mechanisms of human lipodystrophies: from adipocyte lipid droplet to oxidative stress and lipotoxicity. Int. J. Biochem. Cell Biol. 43, 862-876.

Virtue, S. and Vidal-Puig, A. (2010). Adipose tissue expandability, lipotoxicity and the Metabolic Syndrome-an allostatic perspective. Biochim. Biophys. Acta 1801, 338-349.

Wang, L., Jin, Q., Lee, J.E., Su, I.H., and Ge, K. (2010a). Histone H3K27 methyltransferase Ezh2 represses Wnt genes to facilitate adipogenesis. Proc. Natl. Acad. Sci. USA 107, 7317-7322.

Wang, T., Si, Y., Shirihai, O.S., Si, H., Schultz, V., Corkey, R.F., Hu, L., Deeney, J.T., Guo, W., and Corkey, B.E. (2010b). Respiration in adipocytes is inhibited by reactive oxygen species. Obesity (Silver Spring) 18, 1493-1502.

Wang, C.H., Wang, C.C., Huang, H.C., and Wei, Y.H. (2013a). Mitochondrial dysfunction leads to impairment of insulin sensitivity and adiponectin secretion in adipocytes. FEBS J. 280, 1039-1050.

Wang, L., Xu, S., Lee, J.E., Baldridge, A., Grullon, S., Peng, W., and Ge, K. (2013b). Histone H3K9 methyltransferase G9a represses PPARgamma expression and adipogenesis. EMBO J. 32, 45-59.

Wei, J., Zeng, C., Gong, Q.Y., Yang, H.B., Li, X.X., Lei, G.H., and Yang, T.B. (2015). The association between dietary selenium intake and diabetes: a cross-sectional study among middle-aged and older adults. Nutr. J. 14, 18.

Weisberg, S.P., McCann, D., Desai, M., Rosenbaum, M., Leibel, R.L., and Ferrante, A.W., Jr. (2003). Obesity is associated with macrophage accumulation in adipose tissue. J. Clin. Invest. 112, 1796-1808.

Wu, Z., Rosen, E.D., Brun, R., Hauser, S., Adelmant, G., Troy, A.E., McKeon, C., Darlington, G.J., and Spiegelman, B.M. (1999). Cross-regulation of C/EBP alpha and PPAR gamma controls the transcriptional pathway of adipogenesis and insulin sensitivity. Mol. Cell, 3, 151-158.

Xu, J., Kulkarni, S.R., Donepudi, A.C., More, V.R., and Slitt, A.L. (2012). Enhanced Nrf2 activity worsens insulin resistance, impairs lipid accumulation in adipose tissue, and increases 
hepatic steatosis in leptin-deficient mice. Diabetes 61 , 3208-3218.

Yin, R., Mao, S.Q., Zhao, B., Chong, Z., Yang, Y., Zhao, C., Zhang, D., Huang, H., Gao, J., Li, Z., et al. (2013). Ascorbic acid enhances Tet-mediated 5-methylcytosine oxidation and promotes DNA demethylation in mammals. J. Am. Chem. Soc. 135, 10396-10403.

Yoo, H., Stephanopoulos, G., and Kelleher, J.K. (2004). Quantifying carbon sources for de novo lipogenesis in wild-type and IRS-1 knockout brown adipocytes. J. Lipid. Res. 45, 1324-1332.

Zarrouki, B., Soares, A.F., Guichardant, M., Lagarde, M., and Geloen, A. (2007). The lipid peroxidation end-product 4-HNE induces
COX-2 expression through p38MAPK activation in 3T3-L1 adipose cell. FEBS Lett. 581, 2394-2400.

Zhang, Y. and Chen, X. (2011). Reducing selenoprotein P expression suppresses adipocyte differentiation as a result of increased preadipocyte inflammation. Am. J. Physiol. Endocrinol. Metab. 300, E77-85.

Zhang, D.D. and Hannink, M. (2003). Distinct cysteine residues in Keap1 are required for Keap1-dependent ubiquitination of Nrf2 and for stabilization of Nrf2 by chemopreventive agents and oxidative stress. Mol. Cell Biol. 23, 8137-8151.

Zhou, J., Huang, K., and Lei, X.G. (2013). Selenium and diabetes-evidence from animal studies. Free Radic. Biol. Med. 65, 1548-1556. 